\title{
Acute tryptophan administration impairs cortical spreading depression propagation in REM sleep deprived and non- deprived adult rats
}

\author{
Euclides Mauricio Trindade-Filho ${ }^{1}$, Carlos Augusto Carvalho de Vasconcelos ${ }^{2}$ and Rubem Carlos \\ Araújo Guedes ${ }^{2}$
}

1 Universidade Estadual de Ciências da Saúde de Alagoas, Brazil

2 Universidade Federal de Pernambuco, Brazil

\begin{abstract}
The enhanced availability of tryptophan in the brain, as a consequence of exogenous tryptophan administration, can increase neuronal serotonin synthesis and this can interfere with brain function. REM sleep deprivation (D) constitutes another external factor that can change brain excitability, facilitating, in some cases, the manifestation of neurological diseases like epilepsy. Here we used cortical spreading depression (CSD) as a neurophysiological parameter to investigate the effects of a single L-tryptophan intraperitoneal injection combined or not with $72 \mathrm{~h}$ D-condition (water-tank technique) in rats. A $1 \mathrm{~h}$ baseline CSD-recording was performed under urethane+chloralose $(1 \mathrm{~g} / \mathrm{kg}+40 \mathrm{mg} / \mathrm{kg})$ anesthesia and revealed increased CSD propagation velocities in D rats, as compared with non-deprived (ND), or pseudo-deprived (Pseudo) controls. After the baseline CSD recording, L-tryptophan was immediately injected (125 mg/kg ip, dissolved in water at $\mathrm{pH}$ about 3$)$ and this was followed by a significant decrease of CSD propagation velocities, as compared to the baseline values in the same animals of the Pseudo, ND and D condition. In an additional control group (ND rats injected with the vehicle), no CSD propagation change was seen. Our findings indicate an important acute antagonistic influence of tryptophan on CSD propagation, which is not affected by REM sleep deprivation. We suggest that this tryptophan effect may be due to a serotonin-mediated action, probably caused by increased serotonin synthesis as a consequence of enhanced tryptophan availability in the brain. Keywords: L-tryptophan, brain excitability, cortical spreading depression, REM-sleep deprivation, serotonin system.
\end{abstract}

Received 8 October 2009; received in revised form 20 October 2009; accepted 20 December 2009. Available on line 29 December 2009.

\section{Introduction}

The involvement of serotonin-producing neurons in the control of the sleep-wake cycle has been first suggested by Brodie and Shore (1957). Serotonin is synthesized from the essential aromatic amino acid L-tryptophan (Friedman, Kappelman, \& Kaufman, 1972). Therefore, serotonin synthesis can be influenced by changing tryptophan brain availability. In humans, tryptophan administration can lead to a decrease in

Euclides Mauricio Trindade-Filho, Universidade Estadual de Ciências da Saúde de Alagoas, Maceió, AL, Brazil. Carlos Augusto Carvalho de Vasconcelos, Departamento de Nutrição, Universidade Federal de Pernambuco, Recife, PE, Brazil. Rubem Carlos Araújo Guedes, Departamento de Nutrição, Universidade Federal de Pernambuco, Recife, PE, Brazil. Correspondence regarding this article should be directed to: Rubem Carlos Araújo Guedes, Departamento de Nutrição, Universidade Federal de Pernambuco, 50670901, Recife, PE, Brazil. Phone: +55-81-21268936. Fax: +55-81-21268473. E-mail: rc.guedes@terra.com.br / rguedes@ufpe.br wakefulness, as well as to an increase in somnolence, fatigue, lethargy, and diminished sleep latency, probably due to increased serotonin synthesis as a consequence of enhanced tryptophan availability (Leatwood, 1985). The suggestion that serotoninergic neurons could be involved in the sleep control has been further investigated by using drugs that modify the serotoninergic activity (Froment, Petitjean, Bertrand, Conty, \& Jouvet, 1974; Mendelson, Slater, Gold, \& Gillin, 1980).

The daily time spent by mammals in sleeping has been consistently characterized as an electroencephalographically inhomogeneous period, with variations in the EEG pattern that enable us to identify two distinct phases: synchronized and desynchronized sleep, also called "rapid eye movement sleep”, or REM sleep (Aserinski \& Kleitman, 1953). In humans, sleep deprivation is accompanied by signs of fatigue, attention deficit, and irritability with significantly decreased discriminative capacity (Horne, Anderson, \& Wilkinson, 1983). In rats, sleep deprivation for seven days or more causes behavioral changes and 
intense physical exhaustion, followed by the death of the animal, with signs of malnutrition, despite increased food ingestion (Everson \& Wehr, 1993).

Sleep-deprived individuals are more prone to seizures, in comparison with non-deprived controls (Broughton, 1990), supporting the idea that the levels of cortical electrical activity are influenced by sleep deprivation (Kumar \& Raju, 2001; Scalise et al., 2006). The influence of neuronal serotoninergic function on the control of brain electrical activity can be experimentally investigated by using the phenomenon known as cortical spreading depression (CSD). This phenomenon was first described by Leão (1944) as a decrease in spontaneous electroencephalographic activity that can be caused by electrical, mechanical or chemical stimulation of a point on the cortical surface, from which the phenomenon concentrically spreads to remote regions (Leão, 1944). Similarly to what has been observed in sleep studies, CSD has also been shown to be influenced by drugs that enhance the brain serotonin-activity; compounds such as d-fenfluramine (Cabral-Filho, Trindade-Filho, \& Guedes, 1995), citalopram (Guedes, Amancio-dosSantos, Manhães-de-Castro, \& Costa-Cruz, 2002), and fluoxetine (Amâncio-dos-Santos et al., 2006) reduce CSD propagation. However, the possible effects of the serotonin precursor tryptophan on CSD have not been so far investigated. Therefore, this work was undertaken to study, in adult rats, the acute effects of combining L-tryptophan ip administration and REM sleep deprivation on the brain ability to produce and propagate CSD. It was hypothesized that these two conditions, either isolated or combined, would alter CSD propagation features in the rat cortex.

\section{Methods}

\section{Animals}

The animals of this study have been handled in accordance with the "Principles of Laboratory Animal Care" (NIH, Bethesda, USA) and the norms of the Ethics Committee for Animal Research of the Universidade Federal de Pernambuco, Brazil. Fortysix adult Wistar rats weighing between 210 and $320 \mathrm{~g}$ were used. After weaning, they were housed in metallic wire cages measuring $20 \times 30 \times 40 \mathrm{~cm}$ and containing a maximum of 5 animals until the date of the experiment. The animal-room conditions included temperature control (maintained at $22 \pm 2^{\circ} \mathrm{C}$ ) and a 12:12 $\mathrm{h}$ artificial light-dark cycle with the dark phase beginning at 19:00 h. Animals had free access to water and a commercial lab-chow diet (Purina, Brazil.) with 23\% protein.

\section{Sleep deprivation}

The animals were divided in three groups: deprived ( $\mathrm{n}=11)$, pseudo-deprived $(\mathrm{n}=13)$ and non-deprived $(\mathrm{n}=11)$ of REM-sleep (respectively called D, PD, and
ND). Seventy-two hours prior to the electrophysiological recordings, the animals of groups D and PD were placed in individual water-tanks in order to initiate the sleepdeprivation and pseudo-deprivation processes, which took place in the same room where the ND and V rats (see below) were kept. REM sleep deprivation was carried out using the water-tank technique proposed by Jouvet, Vimont, Delorme and Jouvet (1964). The PD animals were exposed to a situation similar to that of group $\mathrm{D}$, differing in the fact that the platform inside the water-tank in which the animals were placed had a larger diameter ( $15 \mathrm{~cm}$ instead of the $6 \mathrm{~cm}$ in the $\mathrm{D}$ condition), large enough to ensure that the animals reached the REM sleep phase without risking contact with the water. The objective of examining this PD group was to control for the possible distressing effects of confinement, reduced motor activity, and humidity to which the $\mathrm{D}$ animals were submitted during the sleep-deprivation procedure.

\section{Tryptophan treatment}

L-tryptophan (Servier Laboratories, France) was injected intraperitoneally in a dose of $125 \mathrm{mg} / \mathrm{kg}$ of body weight. Under environmental temperature conditions, L-tryptophan is in crystalline form, reason for which it had to be diluted in distilled water. For dissolution to occur, a few drops of $0.1 \mathrm{NHCl}$. were also added to the solution. This procedure caused the final $\mathrm{pH}$ of the solution to lower to approximately three.

The three groups described in section 2.2 were injected with L-tryptophan during the CSD recording session. A fourth group $(n=11)$ was composed of nondeprived animals that, instead of L-tryptophan, received an equivalent volume of the vehicle used to dissolve the amino acid [distilled water with an acidic $\mathrm{pH}$ (around three) by addition of $0.1 \mathrm{NHCl}$ drops]. This group was named $\mathrm{V}$ group (from vehicle).

\section{CSD recording}

After the 72-hour deprivation procedure, the animals were intraperitoneally anesthetized with a mixture of $1 \mathrm{~g} / \mathrm{kg}$ urethane plus $0.04 \mathrm{~g} / \mathrm{kg}$ chloralose (both from Sigma, USA) and then underwent tracheotomy followed by the introduction of a tracheal cannula. Under spontaneous breathing, their heads were secured in a stereotaxic device (model 900, David-Kopf) and three holes were drilled on the right side of the skull. The anterior hole, with a diameter of 2 to $3 \mathrm{~mm}$, was drilled on the frontal bone and served as the stimulation site. The two other holes (3-4 mm diameter), drilled on the parietal bone, were aligned with the frontal hole in the anteroposterior direction, parallel to the midline, and served for the placement of the electrodes for CSD recording. Cortex stimulation to obtain the CSD wave consisted of 1-min applications of a small cotton ball (1-2 mm diameter) soaked in $2 \%$ potassium chloride (KCl) solution (approximately $0.27 \mathrm{M} / \mathrm{L}$ ) on one point 
of the cortical surface (frontal hole; dura-mater intact), at 20-min intervals. Both the spontaneous cortical electrical activity (ECoG) and the slow potential change accompanying spreading depression were continuously recorded in a Grass polygraph (model 7D) by using a pair of $\mathrm{Ag}-\mathrm{AgCl}$ agar-Ringer electrodes (one in each parietal hole). These electrodes consisted of $5 \mathrm{~cm}$-long plastic conic pipettes ( $0.5 \mathrm{~mm}$ tip inner diameter), filled with Ringer solution, solidified with the addition of $0.5 \%$ agar, into which a chlorided silver wire was inserted. The pipettes were fixed pair-wise with cyanoacrylate glue, so that the interelectrode distance was kept constant. Each pair of electrodes was connected to a lever, which could be vertically moved up-and-down by turning around a screw, so that the electrode tips could be gently lowered onto the intact dura-mater, under low-power microscope control, without any excessive pressure on the underlying cortical tissue. A common reference electrode of the same type was placed on the nasal bones (see Figure 1 inset).

Calculation of the CSD velocity of propagation was based on the time required for a CSD wave to pass the distance between the two cortical electrodes. This time was measured using the beginning of the rising phase of the negative slow DC-potential change as the initial point. In the first 60 minutes of recording, three measurements of CSD propagation velocity were taken, with $\mathrm{KCl}$ stimulation applied at 20-minute intervals. After this baseline recording period, each group was injected with L-tryptophan (or vehicle, in the case of the $\mathrm{V}$ group) and CSD elicitation and recording continued for two more hours.

\section{Statistics}

Intergroup comparisons of the CSD velocities in the baseline period (before tryptophan treatment) were performed by using one-way ANOVA plus Tukey test, where indicated. CSD velocities in the same animal before and after treatment were compared by using paired $t$ tests. The results were considered significant in the cases where $\mathrm{p} \leq .05$.

\section{Results}

In the 2-h baseline recording period (before L-tryptophan injection), in all groups, 1-min topical application of a cotton ball (1-2 mm diameter) embedded

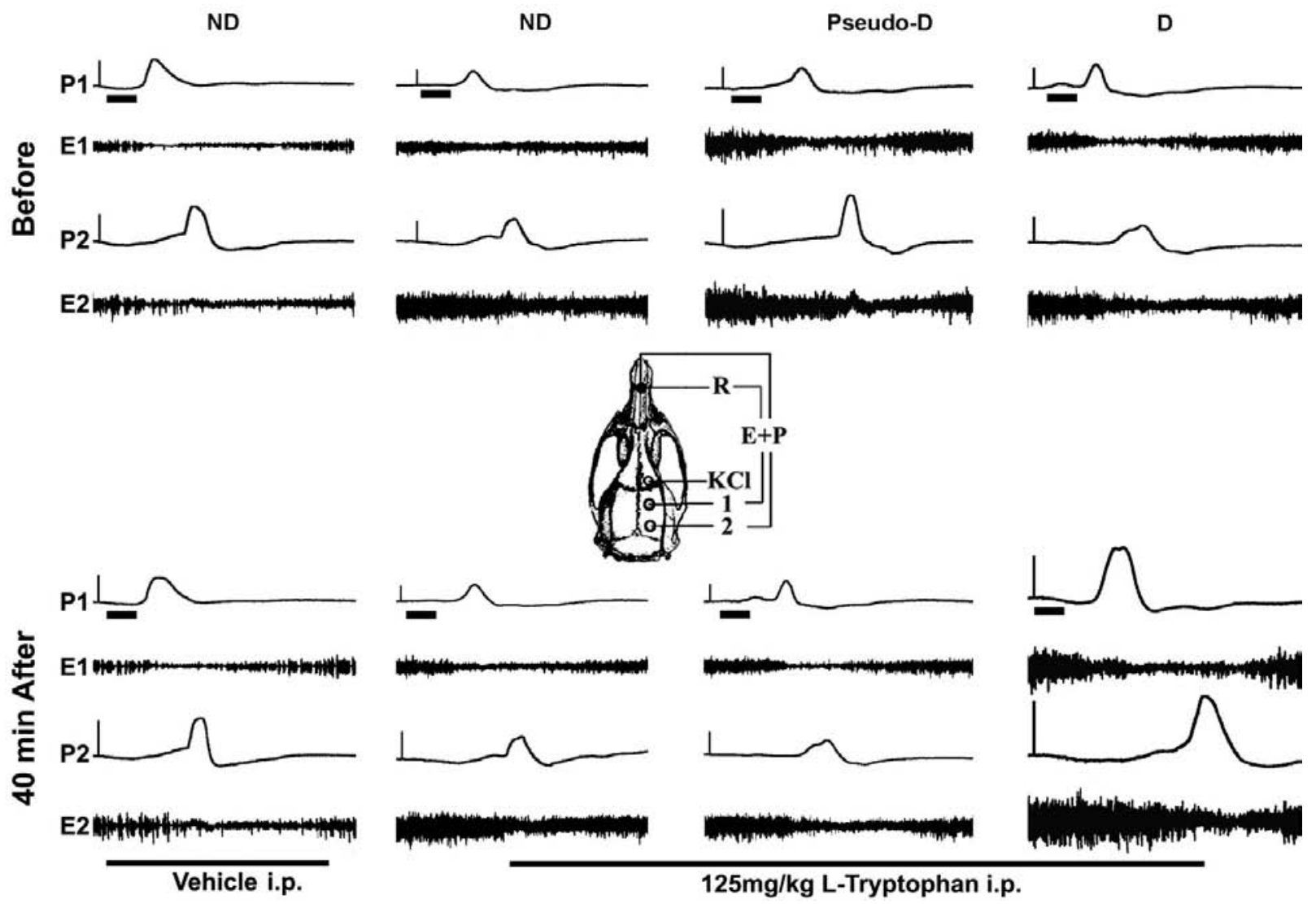

Figure 1. Examples of CSD recordings in REM sleep deprived (D), pseudo-deprived (Pseudo), and non-deprived (ND) rats. The depression of the electrocorticogram (E) and the slow potential change (P) typical of CSD are shown for the recording points 1 and 2, as shown in the inset. The horizontal black bars under the P1-traces denote the period (1 min) of KCl-stimulation to elicit CSD. Upper recordings (above the inset) are from the baseline period (before drug injection). Recordings below the inset were obtained $40 \mathrm{~min}$ after ip injection of either the vehicle used to dissolve tryptophan (left panel), or after ip injection of $125 \mathrm{mg} / \mathrm{kg}$ tryptophan. The vertical bars (at the beginning of each P-record) equal - $10 \mathrm{mV}$ and $-0.5 \mathrm{mV}$ for the P- and E-recordings, respectively. 
in $2 \% \mathrm{KCl}$ to the frontal cortex elicited a single CSD wave, which propagated normally (i.e., without interruption) and was recorded by the two electrodes located in the stimulated hemisphere. Examples of electrophysiological recordings (ECoG and slow potential change) showing CSD elicitation by $\mathrm{KCl}$ are presented in Figure 1.

Before L-tryptophan treatment (baseline period), intergroup comparisons of CSD velocities showed a significant increase $(\mathrm{p}<.05$; ANOVA plus Tukey test $)$ in the animals submitted to REM sleep deprivation (D group; mean \pm sd CSD velocity: $3.95 \pm 0.14 \mathrm{~mm} / \mathrm{min}$ ), but not in the pseudo-deprived ones (Pseudo; $3.36 \pm 0.12$ $\mathrm{mm} / \mathrm{min}$ ), in comparison with the ND controls (3.19 \pm $0.08 \mathrm{~mm} / \mathrm{min}$ ). Quantitative data are shown in Figure 2.

In the three sleep conditions (D, Pseudo, and ND), tryptophan ip injection was followed by a significant decrease $(\mathrm{p}<.05)$ in CSD velocities (Fig. 3), as compared to the velocities measured before the amino acid injection (see Figure 2 and the above description), in the same animals. For these three groups, the mean \pm sd CSD velocities in the six measurements of the post-tryptophan period ranged from $3.18 \pm 0.23$ to 3.39 $\pm 0.18 \mathrm{~mm} / \mathrm{min}$ in the $\mathrm{D}$ group; from $2.82 \pm 0.17$ to $3.01 \pm 0.12 \mathrm{~mm} / \mathrm{min}$ in the ND group, and from 2.83 \pm 0.14 to $3.03 \pm 0.13 \mathrm{~mm} / \mathrm{min}$ in the pseudo group. In the ND group treated with the vehicle used to dissolve tryptophan (distilled water, $\mathrm{pH} 3$ ), no significant decrease in CSD velocities was seen (range: $3.00 \pm 0.17$ to 3.23 \pm 0.10 ). These data are presented on panel A of Figure 3 . When expressed as percentage of the pre-tryptophan injection values, the mean \pm sd CSD velocities in the post-injection period in the ND, pseudo, and D groups corresponded respectively to $84.8 \pm 9.4 \%, 78.4 \pm$ $10.9 \%$, and $73.9 \pm 15.8 \%$ (which indicates significant reductions in the CSD velocity of $15.2 \%, 21.6 \%$, and $26.1 \%$, respectively). In the ND group treated with the vehicle, the post-injection velocity corresponded to 91.8 $\pm 10.7 \%$ of the pre-injection value (panel B of Figure

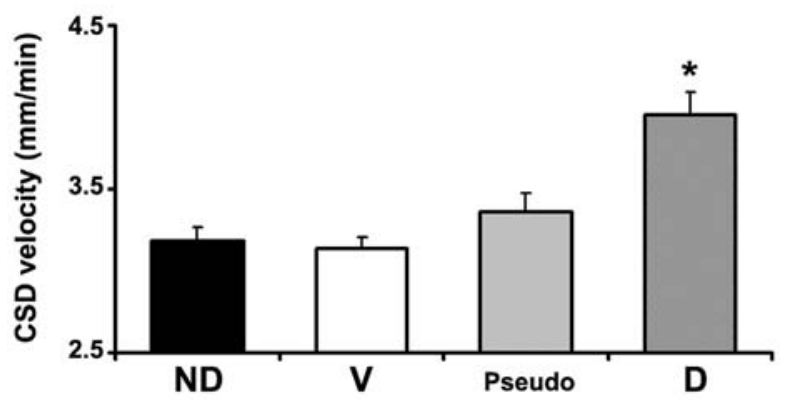

Figure 2. CSD propagation velocity in REM sleep deprived (D), pseudo-deprived (Pseudo), and non-deprived (ND) rats in the baseline period (i.e., before drug injection). Data are presented as mean \pm standard error of the mean. The asterisk indicates significantly higher velocities in the D group, as compared with the other groups $(\mathrm{p}<.05$; ANOVA plus Tukey test).
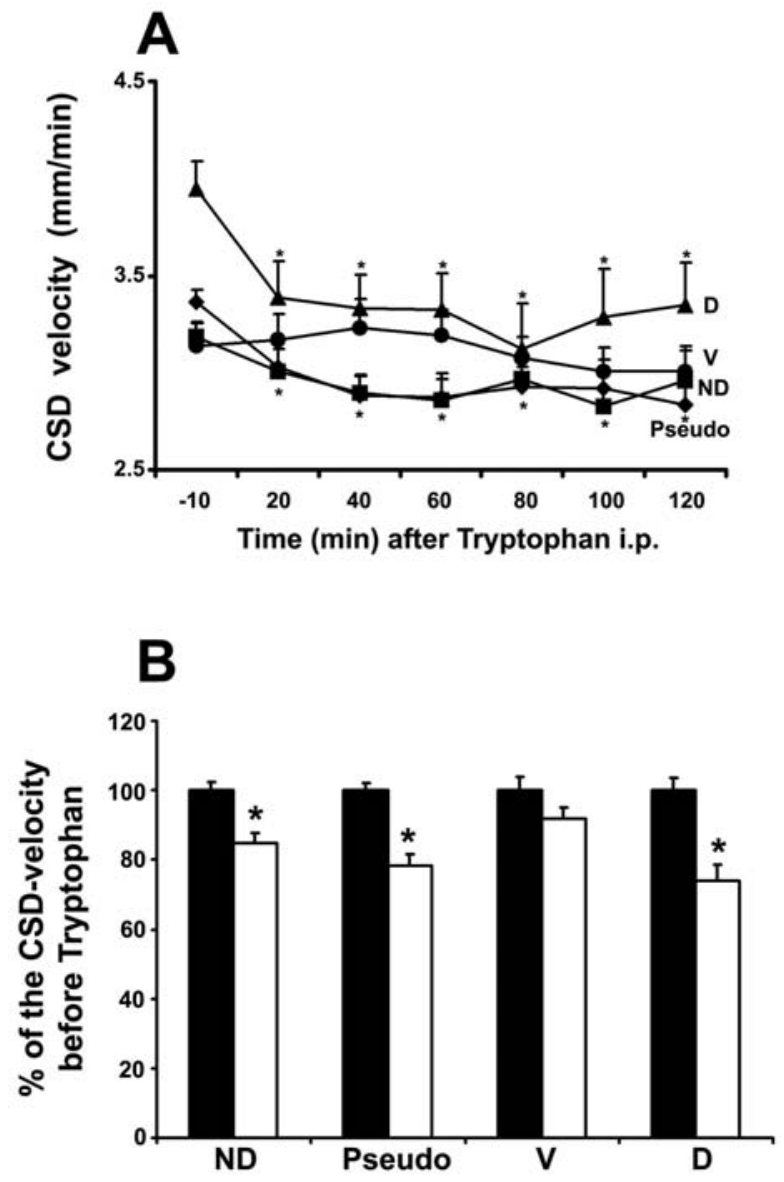

Figure 3. (A) Effect of a single ip injection of $125 \mathrm{mg} / \mathrm{kg}$ L-Tryptophan on the CSD propagation velocity, in REM sleep deprived (D), pseudo-deprived (Pseudo), and non-deprived (ND) rats. CSD velocity was measured every 20 min after L-tryptophan injection. (B) Percentage of reduction of CSD velocity after L-tryptophan (125 mg/kg; single injection; white bars). Data represent percent of the control (pre tryptophan) values for the same animals (black bars). Data are expressed as mean \pm standard error of the mean. The asterisks indicate that all post-injection velocities are significantly reduced, as compared to the pre-injection value at the time point "-10 $\min "(\mathrm{p}<.05$; paired t-test).

3).

\section{Discussion}

The two main findings of the present work are (1) that systemic administration of $125 \mathrm{mg} / \mathrm{kg}$ tryptophan acutely impaired CSD propagation, as evaluated by the lower CSD velocities, and that (2) REM sleep deprivation did not influence this effect. To the best of our knowledge, this is the first study to demonstrate the impairing effect of tryptophan administration on the CSD phenomenon. The results collectively point to an impairing process in CSD propagation, which is probably mediated by tryptophan. One plausible hypothesis to explain our tryptophan-associated results 
is based on the mediation by serotonin, whose synthesis would be expected to increase as a consequence of the treatment with $125 \mathrm{mg} / \mathrm{kg}$ tryptophan, as previously demonstrated (Fernstrom, 1974). This treatment might in all probability alter the inhibition versus excitation balance in the brain tissue (Feria-Velasco et al., 2008), and this may alter CSD susceptibility.

The comparison of the pre-tryptophan CSD velocities between ND and D rats confirmed the findings of previous reports demonstrating a facilitating effect of sleep deprivation on CSD propagation (Amorim, Guedes, da-Silva, \& Cabral-Filho, 1988; Guedes \& Vasconcelos, 2008; Vasconcelos, Oliveira, Costa, \& Guedes, 2004). In addition, although the difference was not significant, the sleep-deprived brains appeared to react even better to the tryptophan administration in regard to CSD impairment.

Although we did not measure cerebral serotonin concentrations, we can infer that the brain content of serotonin might have increased as a consequence of L-tryptophan administration, and this is likely to have impaired CSD propagation. The present CSD propagation changes cannot be attributed to the vehicle used to dissolve the tryptophan or to anesthesia, since the $\mathrm{V}$ group received both the vehicle and the anesthetics and did not present such changes. This inference receives support from the report by Santos and Carlini (1983), who demonstrated that injections of 100 and $150 \mathrm{mg}$ of L-tryptophan were effective in causing serotoninergic syndrome in rats and significantly increased the number of head shakes in comparison to rats injected with saline solution. Moreover, the time course of the effects of our L-tryptophan injection is in agreement with the findings of Fernstrom and Wurtman (1971), who demonstrated that alterations in brain serotonin content were restricted to the first two hours after a single L-tryptophan injection in rats. At this point, it is interesting to mention that the exogenous administration of compounds acting on the serotonin system is effective in modifying the function of this system. For example, serotonin reuptake inhibitors have anticonvulsant activity in GEPRs (Dailey et al., 1996), and the serotonin precursor 5-HTP exerts antiepileptic action against seizures elicited by hippocampal and lateral geniculate nucleus kindling (Wada, Nakamura, Hasegawa, \& Yamaguchi, 1992). In addition, a seizure enhancement has recently been described in pilocarpine-treated rats after serotonin depletion (Trindade-Filho et al., 2008). These results suggest an involvement of the serotoninergic system in suppressing epileptic activity.

Sleep deprivation, and particularly that of REM sleep, is a widely used procedure to increase brain tissue excitability (Baldy-Moulinier et al., 1984; Broughton, 1990). It is employed as part of routine clinical procedures to detect electroencephalographic signs of epilepsy in patients with a clinical history compatible with this disease but with an initial normal EEG. Epileptiform waves can appear and propagate during CSD (Leão, 1944), and the simultaneity of these events led to the idea that the mechanisms of CSD and epilepsy could share some common features (Leão, 1944; 1972). A potentiation effect of brain evoked field potentials (Guedes, Tsurudome, \& Matsumoto, 2005), as well as an LTP-enhancement (Gorji \& Speckmann, 2004), have been demonstrated after induction of CSD, suggesting a CSD-associated facilitation of synaptic transmission. Since it is known that CSD elicitation and propagation depends on the level of excitability in the cerebral cortex (Pinto \& Guedes, 2008), and that several excitabilitychanging environmental, pharmacological, and nutritional manipulations also modify CSD susceptibility (Amânciodos-Santos et al., 2006; Costa-Cruz, Amâncio-dos-Santos, \& Guedes, 2006; De Luca, Cioffi, \& Bures, 1977; Fregni et al., 2007; Guedes, 2005;), it is reasonable to predict that both treatments used in the present study - tryptophan injection and sleep deprivation - could influence CSD propagation features.

The relationship between brain serotoninergic activity and CSD susceptibility shows impaired CSD propagation after increased brain serotoninergic activity. For example, a single ip injection of the specific serotonin releaser d-fenfluramine, administered during the CSD recording session, antagonizes this phenomenon in the adult rat neocortex (Cabral-Filho et al., 1995). Other serotoninergic drugs, like dihydroergotamine (Barkley et al., 1992), 8-OH-DPAT (Kruger, Heinemann, \& Luhmann, 1999), sumatriptan (Read \& Parsons, 2000), citalopram (Guedes et al., 2002) and fluoxetine (Amancio-dos-Santos et al., 2006) also attenuate several CSD features. These data suggest the existence of one or more serotonin-mediated antagonistic processes influencing CSD. In addition to that, the results presented here clearly demonstrate that the serotonin precursor tryptophan impairs CSD propagation in the rat neocortex, reinforcing the notion of CSD modulation by serotonin-dependent processes.

The increase of brain serotonin activity can inhibit the production of free radicals (Read \& Parsons, 2000). This action could be one factor to help explain how the activation of serotoninergic neurons impairs CSD propagation. Increased levels of free radicals in the brain tissue can occur when brain physiological antioxidant mechanisms fail to counteract them (Le Bel \& Bondy, 1992). It is interesting to mention that experimental evidence suggests a crucial role of free radicals in facilitating CSD (El-Bachá, Lima-Filho, \& Guedes, 1998; Guedes, Amorim, \& Teodósio 1996; Netto \& MartinsFerreira, 1989). In addition, antioxidant substances reduce CSD propagation (Abadie-Guedes, Santos, Cahú, Guedes, \& Bezerra, 2008; Bezerra et al., 2005).

At the moment, it is impossible to rule out the possibility that the effects of L-tryptophan on CSD 
reported here are dependent on transmitter systems other than the serotoninergic one. This possibility has to be considered in view of evidence showing that the chronic administration of serotoninergic drugs reduces the levels of N-methyl-D-aspartate (NMDA) receptor subunit mRNA (Boyer, Skolnick, \& Fossom, 1998), probably changing its physiological action. Since NMDAantagonists can antagonize CSD (Guedes, Andrade, \& Cavalheiro, 1988; Marrannes, Willems, De Prins, \& Wauquier, 1988), it would be relevant to investigate, by using pharmacological approaches, the possibility of an indirect involvement of this and other neurotransmitter systems in the CSD effects of L-tryptophan.

In conclusion, by using an acute administration paradigm this study documents the antagonistic effects of tryptophan on CSD, analyzing in detail the two following novel observations: first, a single intraperitoneal injection of tryptophan significantly decreased the CSD propagation in the anesthetized adult rat; second, REM sleep deprivation did not influence the tryptophan effect on CSD propagation. The data reinforce previous evidence (Amâncio-dos-Santos et al., 2006; Cabral-Filho et al., $1995)$ in support of an antagonistic influence of the serotoninergic activity on CSD in the rat.

\section{Acknowledgements}

The authors thank the Brazilian agencies CAPES, CNPq/MS-SCTIE-DECIT - no.17/2006, and IBN-Net (No. 4191) for the financial support. R.C.A. Guedes is a Research Fellow of CNPq (no. 302565/2007-8). This work is dedicated to the memory of professor Luiz Marcelino de Oliveira.

\section{References}

Abadie-Guedes, R., Santos, S.D., Cahú, T.B., Guedes, R.C., \& Bezerra, R.S. (2008). Dose-dependent effects of astaxanthin on cortical spreading depression in chronically ethanol-treated adult rats. Alcoholism: Clinical and Experimental Research, 32, 1417-1421.

Amâncio-dos-Santos, A., Pinheiro, P.C.F., Lima, D.S.C., Ozias, M.G., Oliveira, M.B., Guimarães, N.X., \& Guedes, R.C.A. (2006). Fluoxetine inhibits cortical spreading depression in weaned and adult rats suckled under favorable and unfavorable lactation conditions. Experimental Neurology, 200, 275-282.

Amorim, L.F., Guedes, R.C.A., da-Silva, A.T., \& Cabral-Filho, J.E. (1988). Apomorphine does not mimic the effects of REM-sleep deprivation on cortical spreading depression. Brazilian Journal of Medical and Biological Research, 21, 611-614.

Aserinsk, E., \& Kleitman, N. (1953). Regularly occurring periods of eye motility and concomitant phenomena during sleep. Science, 118, 273-274.

Baldy-Moulinier, M., Touchon, J., Besset, A., Billiard, M., Cadilhac, J., \& Passouant, P. (1984). Sleep architecture and epileptic seizures. In: Degen, R. \& Niedermeyer, E. (Eds.), Sleep and Sleep Deprivation (pp. 107-118). Amsterdam: Elsevier Science Publishers.

Barkley, G.L., Leheta, B.J., Tepley, N., Gaymer, J., Aboukasm, A., \& Welch, K.M.A. (1992). Effects of dihydroergotamine on spreading depression. In: Olesen, J. \& Saxena, P.R. (Eds.), 5-Hydroxytryptamine Mechanisms in Primary Headaches (pp. 236-241). New York: Raven Press.

Bezerra, R.S., Abadie-Guedes, R., Melo, F.R., Paiva, A.M., AmâncioDos-Santos A., \& Guedes, R.C.A. (2005). Shrimp carotenoids protect the developing rat cerebral cortex against the effects of ethanol on cortical spreading depression. Neuroscience Letters, 391, 51-55.

Boyer, P.A., Skolnick, P., \& Fossom, L.H. (1998). Chronic administration of imipramine and citalopram alters the expression of NMDA receptor subunit mRNAs in mouse brain. A quantitative in situ hybridization study. Journal of Molecular Neuroscience, 10, 219-233.

Brodie, B.B., \& Shore, P.A. (1957). On a role for serotonin and norepinephrine as chemical mediators in the central autonomic nervous system. In: Hoagland, H. (Ed.), Hormones Brain Function and Behavior (pp. 161-175). New York: Academic Press.

Broughton, R.J. (1990). Sleep and sleep deprivation studies in epilepsy. In: Wada, J.A. \& Ellingson, R.J. (Eds.), Clinical Neurophysiology of Epilepsy EEG Handbook (pp. 37-43). Amsterdam:Elsevier Science Publishers.

Cabral-Filho, J.E., Trindade-Filho, E.M., \& Guedes, R.C.A. (1995). Effect of d-fenfluramine on cortical spreading depression in rats. Brazilian Journal of Medical and Biological Research, 28, 347-350.

Costa-Cruz, R.R., Santos, A.A., \& Guedes, R.C.A. (2006). Characterization of cortical spreading depression in adult wellnourished and malnourished rats submitted to the association of pilocarpine-induced epilepsy plus streptozotocin-induced hyperglycemia. Neuroscience Letters, 401, 271-275.

Dailey, J.W., Yan, Q.S., Adams-Curtis, L.E., Ryu, J.R., Ko, K.H., Mishra, P.K., \& Jobe, P.C. (1996). Neurochemical correlates of antiepileptic drugs in the genetically epilepsy-prone rat (GEPR). Life Science, 58, 259-266.

De Luca, B., Cioffi, L.A., \& Bures, J. (1977). Cortical and caudate spreading depression as an indicator of neural changes induced by early malnutrition in rats [proceedings]. Activitas Nervosa Superior (Praha), 19, 130-131.

El-Bachá, R.S., Lima-Filho, J.L., \& Guedes, R.C.A. (1998). Dietary antioxidant deficiency facilitates cortical spreading depression induced by photoactivated riboflavin. Nutritional Neuroscience, 1, 205-212.

Everson, C.A., \& Wehr, T.A., 1993. Nutritional and metabolic adaptations to prolonged sleep deprivation in the rat. American Journal of Physiology, 264, 376-387.

Feria-Velasco, A., Mena-Munguía, S., Cárabez-Torres, J., GómezMedrano, A., Recéndiz-Hurtado, F., Orozco-Suárez, S., \& BeasZárate, C. (2008). Low tryptophan and protein in the diet during development increase the susceptibility to convulsions in adult rats. Neurochemical Research, 33, 1484-1491.

Fernstrom, J.D. (1974). Modification of brain serotonin by the diet. Annual Review of Medicine, 25, 1-8.

Fernstrom, J.D., \& Wurtman, R.J. (1971). Brain serotonin content: physiological dependence on plasma tryptophan levels. Science, 173, 149-152.

Fregni, F., Liebetanz, D., Monte-Silva, K.K., Oliveira, M.B., Santos, A.A., Nitsche. M.A., Pascual-Leone, A., \& Guedes, R.C.A. (2007). Effects of transcranial direct current stimulation coupled with repetitive electrical stimulation on cortical spreading depression. Experimental Neurology, 204, 462-466.

Friedman, P.A., Kappelman, A.H., \& Kaufman, S. (1972). Partial purification and characterization of tryptophan hydroxilase from rabbit hindbrain. Journal of Biological Chemistry, 247, 4165-4173.

Froment, J.L., Petitjean, F., Bertrand, N., Conty, C., \& Jouvet, M. (1974). Effects of intracerebral injection of 5,6-hydroxytryptamine on the cerebral monoamines and the states of sleep in the cat. Brain Research, 67, 405-417.

Gorji, A., \& Speckmann, E.J. (2004). Spreading depression enhances the spontaneous epileptiform activity in human neocortical tissues. European Journal of Neuroscience, 19, 3371-3374.

Guedes, R.C.A. (2005). Electrophysiological methods: Application in nutritional neuroscience. In: Liebermann, H., Kanarek, R., \& Prasad, C. (Eds.), Nutritional Neurosciences: Overview of an Emerging Field (pp. 39-54). New York: CRC Press.

Guedes, R.C.A., Amancio-dos-Santos, A., Manhães-de-Castro, R., \& Costa-Cruz, R.R.G. (2002). Citalopram has an antagonistic action on cortical spreading depression in well-nourished and earlymalnourished adult rats. Nutritional Neuroscience, 5, 115-123.

Guedes, R.C.A., Andrade, A.F.D., \& Cavalheiro, E.A. (1988). Excitatory amino acids and cortical spreading depression. In: Cavalheiro, E.A., Lehman, J. \& Turski, L. (Eds.), Frontiers in Excitatory Amino Acid Research (pp. 667-670). New York: Alan R. Liss.

Guedes, R.C.A., Amorim, L.F., \& Teodósio, N.R. (1996). Effect of aging on cortical spreading depression. Brazilian Journal of Medical and Biological Research, 29, 1407-1412. 
Guedes, R.C.A., Tsurudome, K., \& Matsumoto, N. (2005). Spreading depression in vivo potentiates electrically-driven responses in frog optic tectum. Brain Research, 1036, 109-114.

Guedes, R.C.A., \& Vasconcelos, C.A.C. (2008). Sleep-deprivation enhances in adult rats the antagonistic effects of pilocarpine on cortical spreading depression: A dose-response study. Neuroscience Letters, 442, 118-22.

Horne, J.A., Anderson, N.R., \& Wilkinson, R.T. (1983). Effects of sleep deprivation on signal detection measures of vigilance: implications for sleep function. Sleep, 6, 347-358.

Jouvet, D., Vimont, P., Delorme, F., \& Jouvet, M. (1964). Étude de la privation seletive de la phase paradoxale de sommeil chez le chat. Comptes Rendus de la Societé de Biologie (Paris), 158, 756-759.

Krüger, H., Heinemann, U., \& Luhmann, H.J. (1999). Effects of ionotropic glutamate receptor blockade and 5-HT1A receptor activation on spreading depression in rat neocortical slices. Neuroreport, 10, 2651-2656.

Kumar, P., \& Raju, T.R. (2001). Seizure susceptibility decreases with enhancement of rapid eye movement sleep. Brain Research, 922, 299-304.

Leão, A.A.P. (1944). Spreading Depression of activity in the cerebral cortex. Journal of Neurophysiology, 7, 359-390.

Leão, A.A.P. (1972). Spreading Depression. In: Purpura, D.P., Penry, K., Tower, D.B., Woodbury, D.M., \& Walter, R.D. (Eds.), Experimental Models of Epilepsy (pp. 173-195). New York: Raven Press.

Leatwood, P. (1985). Circadian rhythms of plasma amino acids brain neurotransmitters and behaviour. In: Arendt, J., Minors, D.S., \& Waterhouse, J.M. (Eds.), Biological Rhythms in Clinical Practice (pp. 136-157). London: Butterworth \& Co..

Le Bel, C.P., \& Bondy, S.C. (1992). Oxidative damage and cerebral aging. Progress in Neurobiology, 38, 601-609.

Marrannes, R., Willems R., De Prins, E., \& Wauquier, A. (1988). Evidence for a role of the N-methyl-D-aspartate (NMDA) receptor in cortical spreading depression in the rat. Brain Research, 457, 226-240.

Mendelson, W.B., Slater, S., Gold, P., \& Gillin, J.C. (1980). Serotonin inhibition and sleep. Biological Psychiatry, 15, 613-618.

Netto, M., \& Martins-Ferreira, H. (1989). Elicitation of spreading depression by rose bengal photodynamic action. Photochemistry \& Photobiology, 50, 229-234.

Pinto, A.V.O. \& Guedes, R.C.A. (2008). Direct evidence of interhemispheric modulation by callosal fibers: A cortical spreading depression study in well-nourished and early-malnourished adult rats. Experimental Brain Research, 186, 39-46.

Read, S.J., \& Parsons, A.A. (2000). Sumatriptan modifies cortical free radical release during cortical spreading depression. A novel antimigraine action for sumatriptan? Brain Research, 870, 44-53.

Santos, R., \& Carlini, E.L.A. (1983). Serotonin Receptor Activation in Rats Previously Deprived of REM Sleep. Pharmacology, Biochemistry and Behavior, 18, 501-507.

Scalise, A., Desiato, M.T., Gigli, G.L., Romigi, A., Tombini, M., Marciani, M.G., Izzi, F., \& Placidi, F. (2006). Increasing cortical excitability: A possible explanation for the proconvulsant role of sleep deprivation. Sleep, 29, 1595-1598.

Trindade-Filho, E.M., Castro-Neto, E.F., Carvalho, R.A., Lima, E., Scorza, F.A., Amado, D., Naffah-Mazzacoratti, M.G., \& Cavalheiro, E.A. (2008). Serotonin depletion effects on the pilocarpine model of epilepsy. Epilepsy Research, 82, 194-199.

Vasconcelos, C.A.C., Oliveira, J.A.F., Costa, L.A.O., \& Guedes, R.C.A. (2004). Malnutrition and REM-sleep deprivation modulate in rats the impairment of spreading depression by a single sub-convulsing dose of pilocarpine. Nutritional Neuroscience, 7, 163-170.

Wada, Y., Nakamura, M., Hasegawa, H., \& Yamaguchi, N. (1992). Effects of serotonin uptake inhibiting antidepressants on hippocampal kindled seizures in cats. Neuroscience Research Communications, 12, 119-124. 